\title{
Beliefs and Achievement: A Study of Black, White, and Hispanic Children
}

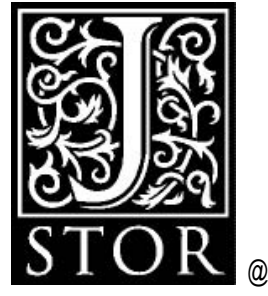

\author{
Harold W. Stevenson; Chuansheng Chen; David H. Uttal
}

Child Development, Vol. 61, No. 2, Special Issue on Minority Children (Apr., 1990), 508-523.

Stable URL:

http://links.jstor.org/sici?sici=0009-3920\%28199004\%2961\%3A2\%3C508\%3ABAAASO\%3E2.0.CO\%3B2-A

Child Development is currently published by Society for Research in Child Development.

Your use of the JSTOR archive indicates your acceptance of JSTOR's Terms and Conditions of Use, available at http://www.jstor.org/about/terms.html. JSTOR's Terms and Conditions of Use provides, in part, that unless you have obtained prior permission, you may not download an entire issue of a journal or multiple copies of articles, and you may use content in the JSTOR archive only for your personal, non-commercial use.

Please contact the publisher regarding any further use of this work. Publisher contact information may be obtained at http://www.jstor.org/journals/srcd.html.

Each copy of any part of a JSTOR transmission must contain the same copyright notice that appears on the screen or printed page of such transmission.

JSTOR is an independent not-for-profit organization dedicated to creating and preserving a digital archive of scholarly journals. For more information regarding JSTOR, please contact support@ jstor.org. 


\title{
Beliefs and Achievement: A Study of Black, White, and Hispanic Children
}

\author{
Harold W. Stevenson, Chuansheng Chen, \\ and David H. Uttal
}

University of Michigan

\begin{abstract}
Stevenson, Harold W.; Chen, Chunansheng; and Uttal, David H. Beliefs and Achievement: A Study of Black, White, and Hispanic Children. CHILD DEVELOPMENT, 1990, 61, 508-523. School achievement among black, white, and Hispanic elementary school children was investigated, and efforts were made to study the beliefs about academic achievement of the children and their mothers. A total of approximately $\mathbf{3 , 0 0 0}$ first, third, and fifth graders enrolled in $\mathbf{2 0}$ schools in the Chicago metropolitan area were given achievement tests in mathematics and reading. Black and Hispanic children performed at a significantly lower level than white children, but at fifth grade ethnic differences in mathematics scores were no longer significant when mothers' education was statistically controlled. This was not the case in reading, where differences were found after controlling for the effects of mothers' education. Interviews with subsamples of approximately 1,000 mothers and children revealed greater emphasis on and concern about education among minority families than among white families. Black and Hispanic children and mothers evaluated the children and their academic abilities highly; they were positive about education and held high expectations about the children's future prospects for education. Mothers of minority children and teachers in minority schools believed more strongly than white mothers and teachers in the value of homework, competency testing, and a longer school day as means of improving children's education.
\end{abstract}

Differences in academic achievement among black, white, and Hispanic children appear early in the elementary school years and persist throughout the elementary and secondary school years. Humphreys (1988) has documented this conclusion in his summary of the results of older national surveys, such as the 1960 Project Talent study, as well as of more recent surveys, such as the 19831984 National Assessment of Educational Progress. Although some evidence indicates improvement in minority children's performance during the past 15 years, the results of other studies suggest that ethnic differences are still large. For example, in a recent report of the performance of 28,000 elementary school students in Montgomery County, Maryland, the percentage of Hispanic and black children who fell behind their white peers in mathematics increased markedly between the first and sixth grades (Norman, 1988). At the second grade, more than $15 \%$ of the black and Hispanic children and approximately $5 \%$ of the white children were performing below grade level. By sixth grade, the performance of $20 \%$ of the white children, while the performance of over $40 \%$ of the Hispanic and $50 \%$ of the black children, was below grade level.

Data such as these are indicative of a problem of growing national concern. The integration of all members of the population into an increasingly complex society is an elusive goal as long as there are low levels of achievement and high dropout rates among black and Hispanic youth. There is obviously a great need for more information about why so many black and Hispanic children and youth are failing to achieve in school.

The lower levels of achievement of minority children have typically been explained in terms of cognitive and linguistic deficits, low need for achievement, lack of

This article reports results from a collaborative study undertaken with James Stigler of the University of Chicago and Shinying Lee and Max Lummis of the University of Michigan. We are grateful for the cooperation of all of the parents, teachers, and children who were involved in this study, and to the school authorities who kindly permitted us to work in their schools. We also thank Michelle Perry, who coordinated the collection of the data, and William Bacon, who assisted us in the preparation of the data for analysis. The research was supported by the William T. Grant Foundation and the National Science Foundation (grant MDR 8751390).Correspondence concerning this article should be addressed to Harold Stevenson, Center for Human Growth and Development, 300 North Ingalls, University of Michigan, Ann Arbor, MI 48109-0406. 
self-direction, low self-esteem, and/or difficulty in delaying gratification (Holliday, 1985). These deficiencies, in turn, have often been attributed to presumed problems in the children's family lives. Black and Hispanic family life frequently has been portrayed in the scholarly literature as bleak, disrupted, and impoverished. Strong disagreement with these characterizations has been registered (e.g., Allen, 1985; Clark, 1983; McAdoo \& McAdoo, 1985; Neisser, 1986; Ogbu, 1985; Ramirez \& Castaneda, 1974). Although the arguments made against such characterizations are compelling, they would be even more so, as Clark has pointed out, if they were backed by empirical data. The need for additional information is especially great in the case of young children. Despite the potential importance of experiences during the elementary school years on later academic achievement, there are relatively few studies of such children before they enter junior high school (e.g., Bartz \& Levine, 1978; Fulkerson, Furr, \& Brown, 1983; Slaughter \& Epps, 1987; Spencer, 1985; Yando, Seitz, \& Zigler, 1979).

Our focus is on the achievement and achievement-related beliefs of black, Hispanic, and white elementary school children. There is ample research documenting differences in achievement among these groups, and the role of beliefs about achievement has been investigated in research with high school students (e.g., Matute-Bianchi, 1986). However, we have found few systematic studies of differences in the beliefs held by black, Hispanic, and white elementary school children and their parents. The most relevant research is that of Willig, Harnisch, Hill, \& Maehr (1983), who studied fourth through eighth graders in metropolitan Chicago. Two explanations of black children's levels of academic achievement were dispelled in this study. The concepts of black children about their ability were as positive as those of white children; thus their performance could not be attributed to lower levels of confidence. Nor could their performance be attributed to a greater tendency to explain achievement outcomes by external factors such as luck. Thus, rather than attempting to explain black children's achievement in terms of variables such as self-concept, anxiety, and attributional patterns, the authors suggested that the relevant motivational variables include the incentive value of education and the individual's perceptions of the utility of academic work. Hispanic children, on the other hand, did demonstrate greater anxiety and a stronger tendency to attribute poor performance to lack of ability than did white or black children. These findings have important implications for the education of minority children, but there clearly is a need for more information about such issues. The present research attempts to address this need.

The research was conducted with a representative sample of children attending elementary schools in the Chicago metropolitan area. We included children who were at the beginning, middle, and end of their elementary school years. We looked at the role parents played in their children's education, at how they believed children can be successful in school, and at the expectations held by the mothers and by the children about the children's future education. We asked mothers and children to evaluate the children's abilities, motivation, and academic performance. Mothers and teachers were asked to consider ways of improving children's performance.

\section{Method}

\section{Subjects}

Our goal was to select a representative sample of children attending public and private elementary schools within the Chicago metropolitan area (Cook County). To constitute this sample, we selected 20 elementary schools covering the range of socioeconomic and ethnic groups within the area. Two classrooms each at first, third, and fifth grades within each school were randomly selected for study. Of 3,215 children enrolled in the classrooms visited, we obtained permission to include 2,973 $(92.5 \%)$ in the group testing of achievement. Our failure to obtain permission for a child's participation was in most cases due to our inability to contact or obtain a response from the child's parents rather than to their refusal to allow the child to participate. Table 1 presents the distribution of subjects by ethnicity. Children's ethnic status was determined from the mothers, or, when mothers were not interviewed, from the children's teachers. The "other" category included children whose ethnic status could not be ascertained, or children who were members of an ethnic group other than black, white, or Hispanic.

Group tests were administered to all of the children in the classrooms, but it was beyond our resources to consider individual testing or interviewing such a large number of children and their parents. We therefore constituted subsamples of children from each school by randomly selecting six boys and six 
TABLE 1

Number of Subjects from Each Ethnic Group

\begin{tabular}{|c|c|c|c|c|c|}
\hline & Black & Hispanic & White & Other & Total \\
\hline \multicolumn{6}{|l|}{ Achievement tests: } \\
\hline Group $\ldots . . .$. & .672 & 433 & 1,561 & 307 & 2,973 \\
\hline Individual $\ldots$ & 99 & 71 & 279 & 22 & 471 \\
\hline Interview (mothers) & 190 & 123 & 623 & 32 & 968 \\
\hline Interview (children & 240 & 174 & 687 & 60 & 1,161 \\
\hline
\end{tabular}

girls from each of two first- and fifth-grade classrooms and three boys and three girls from each of two third-grade classrooms in each of the 20 schools. This yielded a total subsample of 1,200 children, of which we obtained permission for the participation of 1,161 children $(96.8 \%)$. All of the 1,161 children were interviewed. In addition, 471 first and fifth graders were given two individually administered mathematics tests and a test of reading vocabulary. Our goal was to give these tests to 480 children (three boys and three girls from each of 40 classrooms at first and at fifth grades); thus, we were successful in arranging for individual testing of $98.1 \%$ of the subjects in our subgroups.

Children in each ethnic group were similar in age. At grade 1, the means were 6.3 (black), 6.5 years (white), and 6.3 (Hispanic) years. At grade 3, the corresponding ages were $8.5,8.5$, and 8.7 years; and at grade 5 , $10.5,10.5$, and 10.9 years. Over $98 \%$ of the white and black children and $89 \%$ of the Hispanic children were born in the United States.

\section{The Families}

The family structure of the three ethnic groups differed; the biological father was present in fewer than half (39\%) of the black families, in $69 \%$ of the Hispanic families, and in $86 \%$ of the white families. Most of the Hispanic parents were not born in the United States $(69 \%$ of the mothers and $79 \%$ of the fathers were foreign-born), but nearly all of the black parents $(95 \%)$ and most of the white parents $(88 \%)$ were born in the United States. Spanish was spoken at home by most of the Hispanic families (84\%), but only $13 \%$ of the white families and $2 \%$ of the black families spoke a language at home other than English. More white $(55 \%)$ than black $(44 \%)$ or Hispanic $(36 \%)$ mothers were employed.

The average educational level of mothers and fathers in the three ethnic groups also differed greatly; the educational level was lower for Hispanic parents than for black or white parents, and was lower for black than for white parents. The means and standard deviations for the years of education of black, white, and Hispanic mothers were, respectively, $12.8(2.8), 13.8$ (2.7), and 9.8 (3.3) years. Corresponding values for the fathers were 13.2 (3.0), 14.4 (3.0), and 9.3 (4.3) years. The differences among the means were highly significant for both mothers and fathers, $F(2,908 ; 2,822)=96.45 ; 117.78$, p's $<.001$. Income varied widely according to ethnic group: white families had average incomes between $\$ 35,000$ and $\$ 40,000$; and the black and Hispanic families had average incomes between $\$ 15,000$ and $\$ 20,000$. Family income and mother's educational status were significantly related to each other, p's $<.001$, in black, white, and Hispanic families. The respective correlations were $.48, \mathbf{6 0}$, and 34 . However, because of these different degrees of correlation between these two variables. both were included as an index of socioeconomic status. The large percentage of fatherabsent families precluded the use of fathers' level of education and occupation in this index.

\section{Achievement Tests}

The data for this study were collected as part of a larger study of children's academic achievement. In order to increase the likelihood that the children had actually encountered the material on which they were being tested, we constructed cumculum-based tests of achievement in reading and mathematics. Madaus, Kellaghan, Rakow, \& King (1979) have argued that curriculum-based tests are more appropriate as measures of the influence of schooling than are standardized achievement tests. For this purpose, we analyzed two of the most popular series of American textbooks in reading and mathematics. Problems and materials included in the tests were based upon, but not identical to, those in the textbooks. Some tests were constructed for administration to whole classes; others required administration to one child at a time. Group testing occurred during the third month of the 
1985-1986 school year. Testing of individual children began approximately 5 months later.

Group tests. - A group test of mathematical computation contained 76 items arranged in order of difficulty, beginning with items for kindergartners and continuing through items for sixth graders. Items involved concepts such as inequality and numerical order, and skills such as counting, addition, subtraction, division, and multiplication of whole numbers, fractions, and decimals. First graders started with kindergarten items; third graders, with first-grade items; and fifth graders, with third-grade items. The children were allowed $20 \mathrm{~min}$ to solve as many problems as possible. Monitors were present to respond to children's questions about the test.

In the group test of reading comprehension, children were asked to read words or phrases describing one of three pictures and to identifv the victure. to read sentences in which one or two key words were omitted but for which three alternatives for each were available, and to read paragraphs about which multiple-choice questions were asked. First and third graders began at the first-grade level of the test, and fifth graders began at the thirdgrade level. Here, as in the computation test, credit was given for items below the level at which the child began the test (e.g., fifth graders received credit for items below the thirdgrade level).

Individual tests. - Two individually administered tests were given to the subsamples of children in the first- and fifth-grade classrooms. These tests required the application of mathematical concepts and skills to the solution of problems. The tests began with easy items and progressed to more difficult ones. Testing was stopped after the child made four consecutive errors in word problems and five in number concepts.

Word problems contained 28 items of the types children typically encounter in school, such as, "There were 15 bunnies. 9 hopped away. How many were left?" and "A plumber knows that it takes 12 minutes to saw a piece of copper pipe into 3 pieces. How long would it take to saw it into 4 pieces?" We included 31 (first-grade) and 34 (fifth-grade) items in the number concepts test that tapped children's understanding of the meaning and use of numbers and numerical operations. It included such items as (a) "Draw a circle around one-half of the stars" (two linear arrays of unevenly spaced stars were shown to the child), (b) "Here are three digits, 3, 6, 1. How could you arrange these three digits to form the biggest number?" and (c) "Can you tell me another way to say $1 / 2$ ?" The child was provided with a printed version of each problem, and each problem was read to the child. Children were allowed to use paper and pencil.

A test of reading vocabulary also was included. In constructing the test we relied on a data base into which we entered each word in the reading textbooks, along with the grade and semester it was introduced. Six words were selected from the new words appearing at each semester of each grade for inclusion in the test. The test was arranged by grade level. All children began the test at the first-grade level. Testing continued until the child missed eight of the 12 words included at a particular grade level.

The reliabilities (Cronbach alpha) of the group tests were high: .85 at first grade and .86 at fifth grade for the computation test, and .91 at first grade and .80 at fifth grade for the comprehension test. The respective reliabilities for word problems at first and fifth grades were .75 and .81 and for number concepts, .81 and .85 . The reliability for the vocabulary test was .97 at first grade and .94 at fifth grade.

\section{Interviews}

The interviews with the mothers covered a large number of topics, but for this report we rely primarily on items concerning the mothers' beliefs and attitudes about their child's schooling. Out of 1,200 mothers we had sought to interview, we interviewed 968 $(81 \%)$. Depending on the school, the percentage of mothers for whom interviews could be arranged ranged from $48 \%$ to $97 \%$, with a median of $82 \%$. Rate of participation varied according to the mothers' ethnic status. The rates were $79 \%$ for black mothers, $71 \%$ for Hispanic mothers, and $91 \%$ for white mothers. For $6 \%$ of the mothers, face-to-face interviews could not be arranged, but we were able to conduct the interview by telephone. It should be noted that because of the large number of topics about which we sought information, all mothers were not asked the same questions. Some central questions were asked of all the mothers; other questions were asked of only approximately half of the mothers in each ethnic group.

We also interviewed the children. We asked them to evaluate their performance in school, their attitudes about mathematics, reading, and other aspects of school life, their reactions to school and to the subjects they were studying, the effort they expended in study, and their wishes and aspirations. We 


\section{Child Development}

TABLE 2

MEan Scores (and Standard Deviations)for ACHIEvement Tests

\begin{tabular}{|c|c|c|c|}
\hline & \multicolumn{3}{|c|}{ ETHNICITY } \\
\hline & Black & Hispanic & White \\
\hline \multicolumn{4}{|l|}{ Mathematics: } \\
\hline \multicolumn{4}{|l|}{ Computation: } \\
\hline Grade $1 \ldots$ & $11.2(3.8)$ & $11.5(3.2)$ & $14.0(3.1)$ \\
\hline Grade $3 \ldots$ & $25.1(5.1)$ & $24.1(3.5)$ & $25.9(4.3)$ \\
\hline Grade 5 & $44.9(7.8)$ & $43.7(6.4)$ & $46.3(6.0)$ \\
\hline \multicolumn{4}{|l|}{ Word problems: } \\
\hline Grade 1. & $2.7(2.3)$ & $3.3(1.6)$ & $4.0(2.6)$ \\
\hline Grade $5 \ldots \ldots$. & $12.0(4.2)$ & $10.7(3.5)$ & $13.6(3.5)$ \\
\hline \multicolumn{4}{|l|}{ Number concepts: } \\
\hline Grade $1 \ldots \ldots \ldots$ & $13.1(3.9)$ & $13.0(3.9)$ & $16.3(4.5)$ \\
\hline Grade $5 \ldots . .$. & $19.9(5.8)$ & $18.0(5.4)$ & $22.6(5.1)$ \\
\hline \multicolumn{4}{|l|}{ Reading: } \\
\hline \multicolumn{4}{|l|}{ Comprehension: } \\
\hline Grade $1 \ldots \ldots$ & $8.4(6.8)$ & $7.0(5.6)$ & $11.7(7.7)$ \\
\hline Grade $3 \ldots$ & $33.3(8.7)$ & $30.8(7.4)$ & $38.3(8.2)$ \\
\hline Grade $5 \ldots . .$. & $57.0(4.6)$ & $56.0(4.3)$ & $59.5(4.4)$ \\
\hline \multicolumn{4}{|l|}{ Vocabulary: } \\
\hline Grade $1 .$. & $12.4(13.4)$ & $11.6(9.9)$ & $22.0(16.3)$ \\
\hline Grade 5 . & $60.7(9.8)$ & $56.2(13.0)$ & $64.8(6.8)$ \\
\hline
\end{tabular}

NOTE. - For computation and comprehension tests: at first grade, $N$ 's $=\mathbf{2 2 3}$ (black), 134 (Hispanic), 508 (white) ;at third grade, 223 (black), 144 (Hispanic), 506 (white); and at fifth grade, 226 (black), 155 (Hispanic), 547 (white). For word problems, number concepts, and vocabulary: at first grade, N's $=49$ (black), 32 (Hispanic), 122-139 (white); and at fifth grade, 46-50 (black), 33-38 (Hispanic), 121-136 (white).

conducted this interview with all 1,161 children in the subsample. We also interviewed the 120 teachers to obtain their opinions and ideas about improving children's academic performance.

Tests and interviews were conducted by carefully trained black, Hispanic, and white residents of the Chicago area. We matched the ethnic status of the mother and the interviewer whenever possible. Children were tested in English, but Spanish versions of the mother interviews were available, and the interview was conducted in the language the mother preferred.

\section{Results}

The results from the achievement tests will be discussed first, and then we will review factors related to these differences. We discuss the mothers' perceptions of the value of academic achievement, children's attitudes about school, and the expectations of the mothers and children about the child's later academic success. This is followed by a discussion of mothers' evaluations of their child's cognitive, personality, motivational, and academic attributes and of the children's self-evaluations. The accuracy of ratings made by mothers and children of the children's aca- demic abilities is assessed by comparing the ratings with the children's performance in reading and mathematics. We then describe ways in which mothers and teachers believe achievement can be improved.

\section{Achievement Tests}

Mathematics. - Data from the mathematics tests were summarized in Table 2. Scores for all children in each ethnic group are included for the computation test. Scores for word problems and number concepts are based on the subsamples. Analyses of variance conducted separately for each grade yielded consistent significant differences among the three ethnic groups. The effects were as follows: for computation, $F$ 's $\mathbf{s}(\mathbf{2}, 862-$ $2,925)=10.41-69.41, p^{\prime} s<.001$, and for word problems and number concepts, $F^{\prime} \mathrm{s}(2,197-2,214)=6.08-11.46, \mathrm{p}$ 's $<.01$.

Our next step was to determine whether the observed ethnic differences could be attributed primarily to socioeconomic differences as reflected in the educational level of the mothers and family income, variables often found to contribute significantly to the prediction of children's achievement scores (e.g., White, 1982). Analyses of covariance with these variables as the covariates are summarized in Table 3. 
Stevenson, Chen, and Uttal 513

TABLE 3

Significant Effects for Ethnicity on ACHIEvement Tests after Controlling for Mothers' EDUCATION AND FAMILY INCOME

\begin{tabular}{|c|c|c|c|c|}
\hline & $\begin{array}{l}\text { Ethnicity } \\
(F \text { Value })\end{array}$ & $\begin{array}{l}\text { Scheffe } \\
\text { Contrasts }\end{array}$ & $\begin{array}{l}\text { Education } \\
\text { and Income } \\
(F \text { Value })\end{array}$ & $\mathrm{N}$ \\
\hline \multicolumn{5}{|l|}{ Mathematics: } \\
\hline \multicolumn{5}{|l|}{ Computation: } \\
\hline Grade $1 \ldots$ & $10.32 * * *$ & $\mathrm{~B}<\mathrm{W}^{* * *}, \mathrm{H}<\mathrm{W}^{*}$ & $11.39^{* * *}$ & 319 \\
\hline Grade $3 \ldots$ & .68 & & 2.45 & 163 \\
\hline Grade $5 .$. & .38 & & $11.31^{* * *}$ & 304 \\
\hline \multicolumn{5}{|l|}{ Word problems: } \\
\hline Grade $1 \ldots . .$. & $3.50^{*}$ & $\mathrm{~B}<\mathrm{W}^{*}$ & $3.27^{*}$ & 160 \\
\hline Grade $5 \ldots \ldots \ldots \ldots \ldots$ & .33 & & $4.23^{*}$ & 149 \\
\hline \multicolumn{5}{|l|}{ Number concepts: } \\
\hline Grade $1 \ldots \ldots . .$. & $5.31^{* *}$ & $\mathrm{~B}<\mathrm{W}^{* *}$ & $8.92^{* * *}$ & 162 \\
\hline Grade $5 \ldots \ldots \ldots \ldots \ldots$. & .22 & & $7.31^{* *}$ & 137 \\
\hline \multicolumn{5}{|l|}{ Reading: } \\
\hline \multicolumn{5}{|l|}{ Comprehension: } \\
\hline Grade $1 \ldots . .$. . & $6.43^{* *}$ & B \& $\mathrm{H}<\mathrm{W}^{*}$ & $4.04^{*}$ & 319 \\
\hline Grade $3 . . . . .$. . & $4.17^{*}$ & $\mathrm{~B}<\mathrm{W}^{*}$ & $13.76^{* * *}$ & 163 \\
\hline \multirow{2}{*}{\multicolumn{5}{|c|}{ Vocabulary: }} \\
\hline & & & & \\
\hline Grade $1 .$. & 2.32 & & 2.70 & 147 \\
\hline Grade $5 \ldots \ldots \ldots \ldots \ldots \ldots$ & $3.28^{*}$ & & $4.35^{*}$ & 152 \\
\hline
\end{tabular}

At first grade, all three mathematics scores differed significantly according to ethnic status after the effect of mothers' education and family income had been controlled; black children received significantly lower scores than white children on all three tests. However, on the computation test at third grade and on all three mathematics tests at fifth grade, there was little residual effect of ethnicity after controlling for mothers' education and family income. What appeared to be differences in mathematics achievement associated with ethnicity were largely accounted for by consideration of these two, variables reflecting socioeconomic status.

Reading. - The average scores for reading comprehension and vocabulary appear in Table 2. Children from black and Hispanic families received lower scores than white children. Analyses of variance of the scores on the comprehension and vocabulary tests conducted separately by grade yielded highly significant differences: for comprehension, $F ' s(2,862-2,925)=31.06-61.58$, p's $<.001$, and for vocabulary, F's $(2,200 ; 2,220)=11.18$; $15.00, \mathrm{p}$ 's $<.001$.

In contrast to the results for the mathematics tests, differences among the three ethnic groups remained significant on the comprehension test at grades 1,3 and 5, and on the vocabulary test at grade 5 when the contribution of mothers' education and family income to children's scores was controlled (see Table 3).

Sex differences. - Analyses of possible differences between the performance of boys and girls were conducted separately by grade and ethnic group for each of the achievement tests. Very few differences were statistically significant. Among the black children, girls received significantly higher scores than boys for comprehension at first grade and for computation at third grade, p's < .01. Hispanic boys received significantly higher scores than Hispanic girls for comprehension at fifth grade, $\mathrm{p}<.05$. Three differences were significant for the white children, but the pattern of difference was not consistent across the three grades. Girls received higher scores than boys on computation at fifth grade, and boys received higher scores at first grade on word problems and number concepts, p's < .05 .

Attitudes toward Academic Achievement

Value of education. - Mothers rated the importance to them of their child's getting a good grade. The scale ranged from 1 ("not at all important") to 5 ("very important"). Rat- 


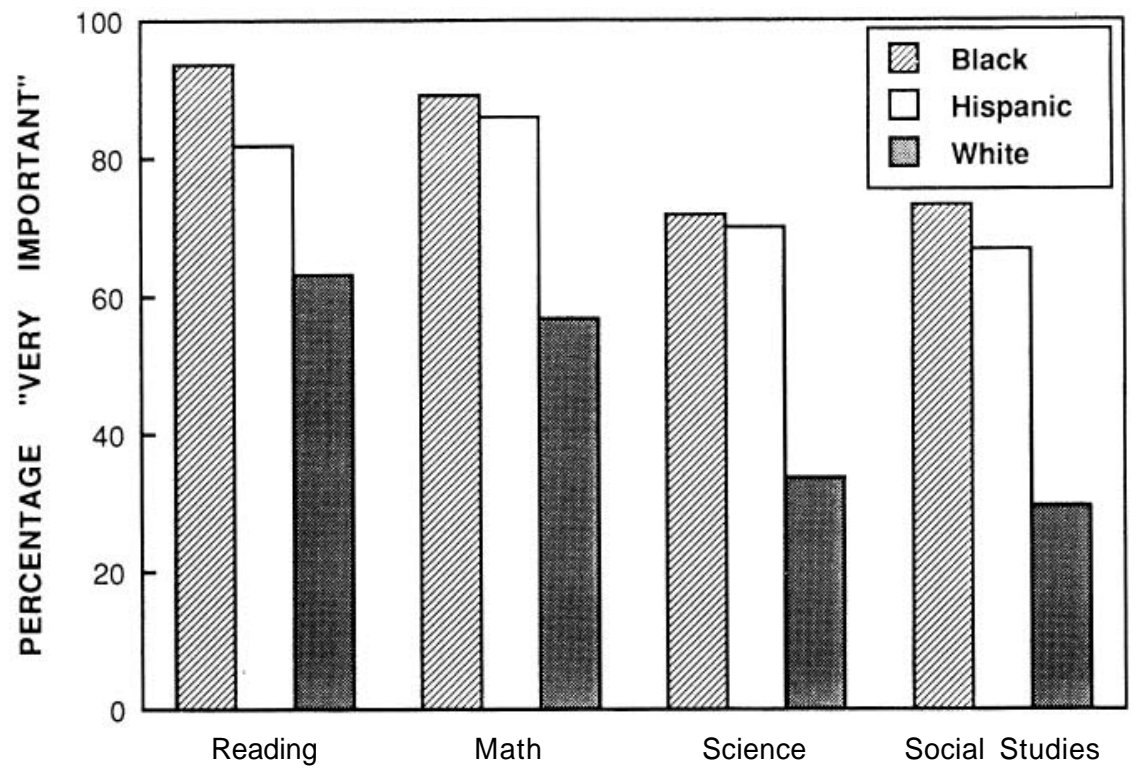

FIG. 1. - Percentages of mothers who considered good grades in four academic subjects to be "very important."

TABLE 4

Mean Ratings by Children of School-Related Topics ( 1 = Dislikes Very Much; 5 = Likes Very Much)

\begin{tabular}{|c|c|c|c|c|c|}
\hline & \multicolumn{3}{|c|}{ ETHNICITY } & \multirow[b]{2}{*}{ F VALUE } & \multirow{2}{*}{$\begin{array}{l}\text { SCHEFFE } \\
\text { ConTrASTS }\end{array}$} \\
\hline & Black & Hispanic & White & & \\
\hline \multicolumn{6}{|l|}{ Grade 1: } \\
\hline Reading & 4.5 & 4.7 & 4.4 & N.S. & N.S. \\
\hline Math .... & 4.0 & 4.4 & 4.0 & N.S. & N.S. \\
\hline School ... & 4.4 & 4.3 & 4.3 & N.S. & N.S. \\
\hline Homework & 4.3 & 4.3 & 3.6 & $4.92 * *$ & $\mathrm{~B}>\mathrm{W}^{*}$ \\
\hline \multicolumn{6}{|c|}{ Grade 3: } \\
\hline Reading & 4.4 & 4.5 & 1.2 & S.S. & S.S. \\
\hline Math & 4.5 & 4.3 & 4.1 & S.S. & S.S. \\
\hline School ... & 4.5 & 4.4 & 3.9 & $6.59^{* *}$ & $\mathrm{~B}>\mathrm{W}^{* *}, \mathrm{H}>\mathrm{W}^{*}$ \\
\hline Homewor & . 4.0 & 3.6 & 2.5 & $25.81 * * *$ & $\mathrm{~B}, \mathrm{H}>\mathrm{W}^{* * *}$ \\
\hline \multicolumn{6}{|c|}{ Grade 5: } \\
\hline Reading & 4.6 & 3.8 & 3.9 & $8.75^{* * *}$ & $\mathrm{~B}>\mathrm{H}, \mathrm{W}^{* *}$ \\
\hline Math ... & 4.4 & 4.4 & 4.1 & N.S. & N.S. \\
\hline School ... & . 4.1 & 4.4 & 3.6 & $8.00^{* * *}$ & $\mathrm{H}>\mathbf{W}^{* *}$ \\
\hline Homework & . 3.5 & 3.8 & 2.7 & $16.19^{* * *}$ & $\mathrm{~B} \& \mathrm{H}>\mathbf{W} \star \star \star \star$ \\
\hline
\end{tabular}

NOTE.--df $s$ for each grade $=(2,180-219)$.

${ }^{*} p<.05$.

${ }^{* *} p<.01$.

$\star * \star p<.001$.

ings were made for reading, mathematics, science, and social studies. Black and Hispanic mothers placed greater importance on their child's academic achievement than did white mothers (see Fig. 1).

Children's attitudes toward school.The children generally were positive about reading and mathematics (see Table 4). They gave high ratings to both of these subjects, and only at fifth grade did a significant difference appear: black fifth graders liked reading better than Hispanic and white children. Black and Hispanic children liked homework more than did white children, and this pattern of difference was statistically significant at 
TABLE 5

Mothers' Ratings of Children's attitudes toward School $(1=$ Never, $5=$ Always $)$

\begin{tabular}{|c|c|c|c|c|c|}
\hline & \multicolumn{3}{|c|}{ ETHNICITY } & \multirow[b]{2}{*}{ F VALVE } & \multirow{2}{*}{$\begin{array}{l}\text { SCHEFFÉ } \\
\text { CONTRASTS }\end{array}$} \\
\hline & Black & Hispanic & White & & \\
\hline $\begin{array}{l}\text { Looks forward to doing } \\
\text { homework ........... }\end{array}$ & 3.2 & 3.9 & 2.6 & $33.12 * * *$ & $\mathrm{H}>\mathrm{B}>\mathrm{W}^{* *}$ \\
\hline $\begin{array}{l}\text { Talks about teachers } \\
\text { positively .......... }\end{array}$ & 3.7 & 4.2 & 3.9 & $3.43^{*}$ & $\mathrm{H}>$ \\
\hline Comes home from school & & & & & $11>0$ \\
\hline happy $\ldots \ldots \ldots \ldots \ldots$ & 4.2 & 4.5 & 4.2 & $6.36^{* *}$ & $\mathrm{H}>\mathrm{W}^{* *}$ \\
\hline $\begin{array}{l}\text { Can't wait for vacations } \\
\text { to end } \ldots \ldots \ldots\end{array}$ & 2.8 & 3.1 & 2.5 & $7.7^{* * *}$ & $\mathrm{H}>\mathrm{W}^{* *}$ \\
\hline $\begin{array}{l}\text { Eager to go to school in } \\
\text { the morning } \ldots \ldots \ldots\end{array}$ & 4.1 & 4.4 & 3.8 & $12.27 * * *$ & $\mathrm{~B}>\mathrm{W}^{*}$ \\
\hline $\begin{array}{l}\text { School is too long and } \\
\text { boring } \ldots \ldots \ldots \ldots\end{array}$ & 1.5 & 1.5 & 2.0 & $16.34^{* * *}$ & $\begin{array}{l}\mathrm{H}>\mathrm{W}^{* * *} \\
\mathrm{~W}>\mathrm{B}^{* * *} \\
\mathrm{~W}>\mathrm{H}^{* * *}\end{array}$ \\
\hline
\end{tabular}

Note. $-N$ 's $=96-98$ (black); 326-356 (white); 60-61 (Hispanic).

${ }^{*} \mathrm{p}<.05$.

$* * p<.01$.

$* * * \mathrm{p}<.001$.

both first and fifth grades. At first grade, all three groups were equally positive about school, but by third grade the white children's fondness for school had waned, so that their ratings were significantly below those of both the black and Hispanic children.

Mothers seemed to agree with their children's opinions. They perceived their child as being positive about school, but black and Hispanic mothers portrayed even greater enthusiasm on the part of their child than did the white mothers. Hispanic and/or black mothers were more likely than white mothers to believe that their child spoke positively about the teacher, looked forward to homework, came home from school happy, could not wait for vacations to end, and was eager to go to school each moming (see Table 5). In addition, black and Hispanic mothers were less likely to believe that their child found school too long and boring than were the white mothers.

Expectations for future education. - We asked fifth graders to predict how well they would do in high school mathematics and reading. Black and Hispanic children were very optimistic. For their predictions about mathematics, their average ratings were 4.0 (black), 3.6 (white), and 3.8 (Hispanic) on a scale ranging from 1 (among the worst) to 5 (among the best), $F(2,223)=4.52, \mathrm{p}<.05$. They were equally positive about how well they would do in reading; the respective ratings were $4.2,3.8$, and 4.1, $F(2,224)=6.00$, p
$<.01$. In each case the lowest ratings were made by the white children.

Of the Hispanic mothers, 55\% believed their child would go only as far as high school; $43 \%$ believed their child would go to college. Black and white mothers had even higher expectations. Only $32 \%$ of the black mothers thought their child would go no further than high school; 63\% thought their child would attend college. Among white mothers, the comparable percentages were $25 \%$ and $71 \%$. The children held still higher expectations: $93 \%$ of the black children, $80 \%$ of the white children, and $71 \%$ of the Hispanic children believed they would attend college. These expectations are in dramatic contrast with current national statistics. In 1988, the national average for completion of high school for white Americans of ages 18 and 19 was $77 \%$; for black Americans, $65 \%$; and for Hispanic Americans, 55\% (Bennett, 1988).

Evaluations of the Children

Ratings by mothers. - Black and Hispanic mothers' evaluations of their children were very positive. The mothers evaluated their child's (a) cognitive abilities, such as memory, learning ability, and intelligence; (b) personality characteristics, such as obedience, excitability, outgoingness, happiness, and self-confidence; (c) motivational characteristics, such as enthusiasm about learning, working hard on reading and mathematics, and wanting to do well in school; and (d) levels of achievement in reading and mathe- 


\section{Child Development}

matics. On none of the scales was the mean rating made by any of the ethnic groups below 3.0, the value that was described as "average" on the 5-point ratings scales. For example, ratings of their child's level of achievement in reading after adjusting for mothers' education and family income were 3.8 for all three groups of mothers, and for mathematics, 3.7, 3.7, 4.0 for black, white, and Hispanic mothers, respectively. Ethnic differences were statistically significant in only two comparisons after controlling for mothers' education and family income. Black mothers gave higher ratings to their child on scales of intelligence and excitability than did the Hispanic mothers, p's $<.05$.

The three groups of mothers did not differ significantly in their beliefs about how well-adjusted their child was in school or in their descriptions of somatic complaints such as headaches, of tension patterns such as having difficulty in sitting still, or of their child's social adjustment. However, a higher percentage of black (22\%)and white (18\%) than of Hispanic mothers (4\%) believed that their child "gets too much pressure about schoolwork," $\chi^{2}(2, \mathrm{~N}=347)=7.03, \mathrm{p}<.05$.

Ratings by children. - In line with the ratings made by their mothers, the children tended to rate themselves as being above average in reading and mathematics. Ratings were made on 5-point rating scales in which 5 was defined as being "among the best" and 3 as "average." Generally, black children tended to give themselves higher ratings than did the Hispanic and white children, but ethnic differences were significant only for reading at third and fifth grades. The mean ratings for reading ability by third graders were 4.2 (black), 3.7 (white), and 4.0 (Hispanic), $F(2,219)=4.55, \mathrm{p}<.05$; at fifth grade the respective means were $4.0,3.7$, and 3.4 , $F(2,210)=5.54, \mathrm{p}<.05$. Comparing this set of ratings with children's expectations of their performance in high school (presented in an earlier section), black and Hispanic children appear to have thought their academic status would improve, but the white fifth graders did not. All differences for black and Hispanic children were significant, $t$ 's $(38-49)=$ $2.68-4.39, p$ 's $<.05$, except for the black children's ratings of mathematics.

Fifth graders also were asked how hard mathematics and reading were for them and how hard they worked. There were small but significant ethnic differences in their ratings of the difficulty of reading and in their perceptions of how hard they worked in reading and in mathematics, $F$ 's $(2,224-2,227)=3.41-$ 7.43 , p's $<.05$. The ratings indicated that black children believed reading was easier and that they worked harder in reading and in mathematics than did the white and Hispanic children. The mean ratings made by black children on these three variables were, respectively, 4.2, 4.4, and 4.5. For Hispanic children they were $3.5,3.7$, and 4.0. For white children they were $3.8,4.0$, and 4.2.

Children in the three ethnic groups held similar beliefs about how pleased they thought their parents and teachers were with their performance in mathematics (the mean ratings for the three ethnic groups were all toward the "very pleased" end of the 5-point scale, ranging from 3.9 to 4.3 ). The three ethnic groups also were similar in their perceptions of how pleased their teachers were with their reading performance. In their ratings of how pleased their parents were with their reading, however, black children believed their parents were more pleased than did white and Hispanic children, $F(2,221)=$ $4.08, \mathrm{p}<.05$. The mean ratings were 4.5 (black), 4.1 (white), and 3.9 (Hispanic).

Relations between ratings and achieuemerit.-Ratings made by the mothers and the children concerning the children's ability in reading and mathematics may or may not be valid in terms of the child's actual level of achievement. Because measures of performance were available, it was possible to correlate the ratings with the children's scores. This was done for mathematics and reading separately for each grade and each ethnic group. Here and in later instances unless noted, the comprehension and computation tests have been used as the measures of achievement in reading and mathematics. All of the correlations between mothers' ratings of how well their child was doing in reading and in mathematics and the child's achievement scores were statistically significant: white mothers, mean $r(588)=.43$; black mothers, mean $r(160)=.34$; and Hispanic mothers, mean $r(106)=.30$, p's $<.01$. Among the ratings made by the children, however, only the ratings made by the white children were significantly related to their achievement scores, mean $r(664)=.24, \mathrm{p}<$ .001 . The mean correlation was .10 for the black children and .18 for the Hispanic children. (The mean correlation for each ethnic group in these computations was determined after submitting the separate correlations for each grade to a Fisher $r$ to $z$ transformation.) 

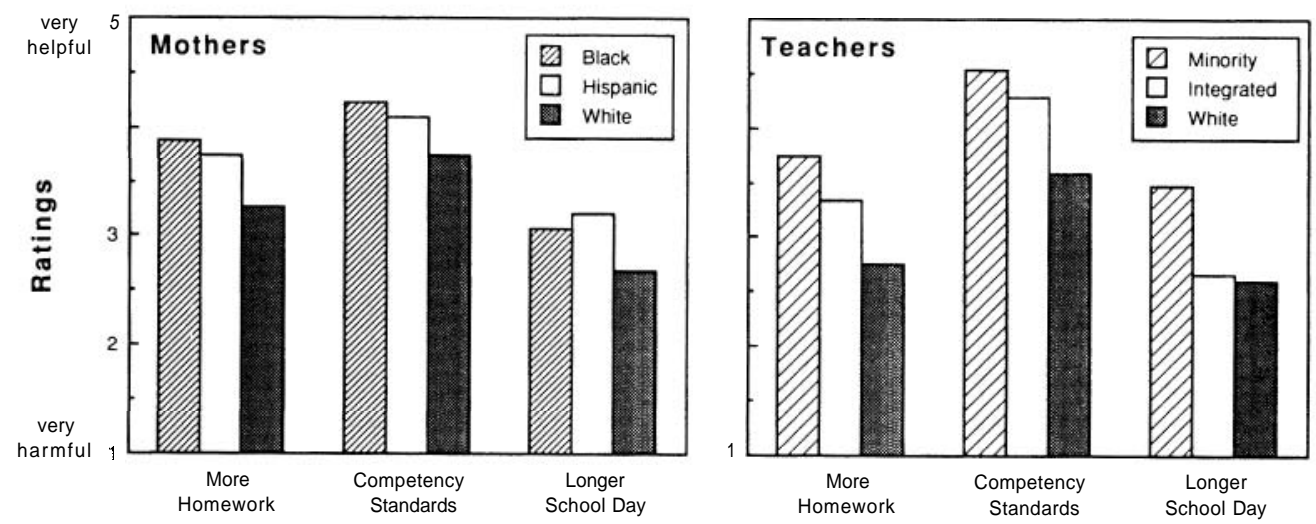

FIG. 2.- Mothers' and teachers' ratings of the effectiveness of homework, competency testing, and increasing the length of the school day in improving children's performance. For mothers: $F^{\prime} s(2,330-2,334)$ $=8.27-14.08$, p's $<.001$. For teachers: $F^{\prime} s(2,73)=4.31-8.30$, p's $<.05$.

\section{Improving Children's Performance}

Mothers' and teachers' opinions. - The intense interest in educational reform during the past several years has led to many suggestions about ways to improve the educational system (e.g., Bennett, 1988). We asked the mothers to respond to a number of these suggestions. Generally, black and Hispanic mothers were more positive about the suggestions for improvement than were the white mothers. Three of the most extreme differences in opinion concerned homework, competency testing, and a longer school day (see Fig. 2). Increasing the amount of homework was considered to be helpful for improving children's performance by $88 \%$ of the black mothers, $74 \%$ of the Hispanic mothers, but by only $46 \%$ of the white mothers. This is especially remarkable in view of the fact that the black and Hispanic children already were doing more homework than the white children. According to their mothers' estimates, the children were spending an average of 6.7 hours (black), 6.2 hours (Hispanic), and 4.1 hours (white) per week on homework, $F(2,531)=15.24, \mathrm{p}<.001$. Similarly, more black $(95 \%)$ and Hispanic $(89 \%)$ than white mothers $(71 \%)$ believed it would be helpful for children's education if competency standards were established for promotion from one grade to the next. In addition, black and Hispanic mothers were more positive about lengthening the school day. Mothers in the three ethnic groups were equally positive about devoting more time to mathematics (74\%-78\% of the mothers in each group) and reading $(77 \%-85 \%)$. All three groups believed there was a need for smaller classes $(87 \%-95 \%)$ and that children should be given more individualized instruction $(91 \%-94 \%)$.
Fewer mothers (33\%-43\%) expressed enthusiasm about lengthening the school year.

How closely did the opinions of the mothers agree with those of their child's teacher? We looked at the answers of teachers in schools differing in the ethnic status of their pupils in answering this question. Teachers were not assigned to schools according to their own ethnic status; thus it seemed more reasonable to conduct the analyses by the type of students taught than by attempting to analyze the data separately according to the ethnic status of the teachers. Schools were defined as being black, white, or Hispanic schools if $80 \%$ or more of the children attending the school were of one ethnic group. This resulted in designating four schools as black, nine as white, one as Hispanic, and six as integrated. No more than two-thirds of the children in integrated schools were from one ethnic group. Because of the small number of black and Hispanic schools and because of the similarity of their ratings, data for the teachers in these schools have been combined.

We asked the first- and fifth-grade teachers about the same activities we had discussed with the mothers. As shown in Figure 2 , the teachers in minority and integrated schools expressed stronger agreement than did the teachers in the white schools that there should be more homework, competency testing, and a longer school day. In addition, they were more likely than teachers in white schools to favor having smaller classes, and spending more time on mathematics, reading, and science. The average difference between the ratings of the teachers in the minority and those in white schools concerning these fac- 


\section{Child Development}

tors was between .6 and .9 points, $F$ 's $(2,73-$ $2,74)=5.49-8.47$, p's $<.01$. The lower interest of teachers in white schools in reducing class size is probably related to the fact that the white schools had fewer children in each classroom (mean $=23$ ) than the minority and integrated schools (respective means $=31$ and 29).

Teachers in minority schools believed that more homework should be assigned, even though they already were assigning homework requiring more time than that assigned by the teachers in the white schools. The teachers estimated the average number of minutes required to complete the previous week's homework assignments. The respective means for the minority, white, and integrated schools were 102, 62, and $97 \mathrm{~min}$ (mathematics); 106, 38, and 85 min (reading); and 23,15 , and $36 \mathrm{~min}$ (social studies), $F^{\prime} \mathrm{s}(2,101-2,110)=3.26-12.25, \mathrm{p}$ 's $<.05$.

Role of parents. - The mothers agreed that parents should work closely with their children on schoolwork, but agreement was greater among black and Hispanic mothers. This beiief was expressed by $95 \%$ of the black mothers, $96 \%$ of the Hispanic mothers, and $80 \%$ of the white mothers, $x^{2}(2, N=345)=$ $14.54, \mathrm{p}<.001$. Agreeing with the suggestion that mothers should work with their children on schoolwork did not necessarily mean that they believed they were capable of providing this assistance. Most of the black (98\%) and white $(97 \%)$ mothers, but only $77 \%$ of the Hispanic mothers, believed they could help their child in reading, $\chi^{2}(2, \mathrm{~N}=347)=32.94, \mathrm{p}<$ .001. A similar effect was found for mathematics; more black and white mothers $(86 \%$ and $86 \%)$ than Hispanic mothers (66\%) believed they were capable of helping their child, $\chi^{2}(2$, $\mathrm{N}=346)=11.64, \mathrm{p}<.01$.

Black and Hispanic mothers were more likely than white mothers to say they would like to be doing more to help their child. The question was asked only about mathematics. Many more black $(71 \%)$ and Hispanic mothers $(61 \%)$ than white mothers $(39 \%)$ believed there were things they could not do but would iike to be able to do in order to help their child with mathematics, $x^{2}(2, \mathrm{~N}=$ $340)=24.47, \mathrm{p}<.001$.

Not only did the black mothers give greater emphasis to the importance of helping their child with schoolwork, they also reported being more likely to provide such help than did white and Hispanic mothers. When asked whether they believed they spent a great deal of time working with their child on homework, black mothers expressed stronger agreement than white and Hispanic mothers. Their mean ratings on a scale that ranged from 1 ("strongly disagree") to 5 ("strongly agree") were 3.8 (black), 3.3 (white), and 3.1 (Hispanic), $F(2,344)=7.73, \mathrm{p}<.001$. Black mothers also gave higher estimates than white or Hispanic mothers of the amount of time they spent helping their child with schoolwork. In their weekly estimates of the help given, black, white, and Hispanic mothers estimated that they spent, respectively, 185, 130, and 114 min helping their child with reading, $F(2,346)=4.19, \mathrm{p}<.05$, and 137,70 , and $86 \mathrm{~min}$, respectively, helping their child with mathematics, $F(2,347)=$ $10.38, \mathrm{p}<.001$. Black mothers were more likely than white and Hispanic mothers to believe that mothers' help actually can improve children's performance. The mean ratings were $4.1,3.4$, and 3.1 for the black, white, and Hispanic mothers, $F(2,545)=16.52, \mathrm{p}<.001$. The scale ranged from 1 ("of little help") to 5 ("of great help").

Preschool knowledge. - A final question was whether there were consistent differences among the three ethnic groups in the amount of preparation parents gave their children for school. Mothers were asked what they had taught their child before the child entered elementary school. Hispanic mothers reported providing significantly less instruction to their child than white or black mothers, who provided about the same amount of early instruction. The mothers were asked whether they attempted to teach their child the alphabet; to read words, stories, and numbers; and to count, add, and subtract (see Table 6). A summary score composed of the response to these seven items yielded means of 3.5 for the Hispanic mothers, 4.9 for the black mothers, and 4.6 for the white mothers, $F(2,376)=7.98, \mathrm{p}<.001$.

We also asked mothers about what their child was capable of doing before entering first grade. Hispanic children were reported to have acquired fewer school-related skills, such as reading the alphabet, writing their name, and reading numerals, than white or black children. Hispanic mothers said their child could do an average of 3.5 of the seven items; black mothers, 4.4; and white mothers, 4.8. The differences were significant, $F(2,556)$ $=16.19, \mathrm{p}<.001$.

For both blacks and whites, estimates made by mothers of first graders of what their child could do before entering school were predictive of their child's scores on the tests 
TABLE 6

Percektage of Mothers Who Taught Their Preschool Children

\begin{tabular}{|c|c|c|c|c|c|}
\hline & \multicolumn{3}{|c|}{ ETHNICITY } & \multirow[b]{2}{*}{$x^{2}$} & \multirow{2}{*}{$\begin{array}{l}\text { BOKFERONI } \\
\text { CONTRASTS }\end{array}$} \\
\hline & Black & Hispanic & White & & \\
\hline Alphabet . & 100 & 72.9 & 91.1 & $23.38^{* * *}$ & $\begin{array}{l}\mathrm{B}>\mathrm{W}^{*} \\
\mathrm{~B}>\mathrm{H}^{* * *} \\
\mathrm{~W}>\mathrm{H}^{* *}\end{array}$ \\
\hline Read words & 76.6 & 53.2 & 65.8 & $6.63^{*}$ & $\mathrm{~B}>\mathrm{H}^{*}$ \\
\hline Read stories . & 61.9 & 37.5 & 43.6 & $8.33^{*}$ & $\begin{array}{l}\mathrm{B}>\mathrm{W}^{*} \\
\mathrm{~B}>\mathrm{H}^{*}\end{array}$ \\
\hline Counting ........... & 98.4 & 70.2 & 91.1 & $24.85^{* * *}$ & $\begin{array}{l}\mathrm{B}>\mathrm{H}^{* * *} \\
\mathrm{~W}>\mathrm{H}^{* *}\end{array}$ \\
\hline $\begin{array}{l}\text { Read numbers ....... } \\
\text { Add }\end{array}$ & 90.6 & 79.2 & 89.4 & 4.46 & \\
\hline $\begin{array}{l}\text { Add } \ldots \ldots \ldots \ldots \ldots \ldots \\
\text { Subtract } \ldots \ldots \ldots \ldots \ldots\end{array}$ & $\begin{array}{l}73.0 \\
58.1\end{array}$ & $\begin{array}{l}44.0 \\
32.0\end{array}$ & $\begin{array}{l}59.4 \\
41.2\end{array}$ & $\begin{array}{r}10.56^{* *} \\
9.64^{* *}\end{array}$ & $\begin{array}{l}\mathrm{B}>\mathrm{H}^{* *} \\
\mathrm{~B}>\mathrm{W}^{*} \\
\mathrm{~B}>\mathrm{H}^{*}\end{array}$ \\
\hline
\end{tabular}

NOTE. - N's ranged from 345 to 363 .

${ }_{* *}^{*} \mathrm{p}<.05$.

$\star * x>.01$.

$* * * p>.001$.

of reading and mathematics achievement in first grade $\left(\mathrm{r}^{\prime} \mathrm{s}=.41-.64, \mathrm{p}\right.$ 's $<.01 ; \mathrm{d}=41$ for black and 126 for white). Not one of the correlations was significant for the Hispanic children. It is impossible to know whether Hispanic mothers were inaccurate in their estimates, whether the children were unable to transfer what they had learned in Spanish at home to the English-speaking classroom, or whether for some reason there literally was no relation between the skills of Hispanic children before they entered school and their achievement in the subjects taught in school.

\section{Response Style}

It has been suggested by Bachman and O'Malley (1984) that black adolescents display a greater tendency than whites to use the extreme ends of rating scales. To determine if such a response style could explain the differences in ratings obtained from the mothers and elementary school children in the present study, we collapsed the scales from 5-point to 3-point scales. Analyses were recomputed for all scales on which main effects for minority status were found. When this was done for the ratings made bv the children. there were few departures fromthe effects obtained with the full scales. For example, of the ratings made on the attitude scales, all effects described in Table 4 were replicated. Similarly, of the effects described for the mothers' ratings in Table 5, statistical significance was maintained for all but two of the sets of ratings. In no case did the reanalysis reveal a reversal in the direction of the difference in ratings. We find little basis, therefore, for attributing the effects found in this study to differences in response styles of minority and nonminority individuals.

\section{Discussion}

Because a large amount of information has been presented, we first summarize the major findings, especially those that describe characteristics of each ethnic group.

Hispanic families. - Hispanic mothers' lack of familiarity with the American school system and the English language may have made it difficult for them to assess their children's level of performance in American schools. Nevertheless, they sought to help their children with their schoolwork and to emphasize the importance of school to their children. They apparently provided less academic preparation to their children prior to entering school than did white and black parents, presumably because they were less familiar with the demands that would be placed on their children. Hispanic mothers, like black and white mothers, regarded their children's abilities highly and believed their children were doing satisfactorily in school.

Hispanic mothers were eager to be helpful to their children but believed that they were less capable of helping their children and that their help was less likely to contribute to their child's achievement than was the case with the black and white mothers. They did, however, wish that they were able to do more to help their children. Hispanic mothers, along with black mothers and with teachers in minority schools, believed strongly 


\section{Child Development}

in the utility of homework, the necessity of competency examinations, and the potential value of a longer school day. Their expectations for their child's future were lower than those of the black and white mothers, but nevertheless were high.

In characteristics such as the importance of getting good grades in school and liking homework, school, and reading, Hispanic children were more similar in their attitudes to the black children than to the white children. Hispanic children liked school, were optimistic about their future performance, and believed their performance would improve in subsequent years. They did not rate themselves as working as hard as white and black children but were positive and believed both their teachers and parents were pleased with their performance.

Blackfamilies. - There were both strong similarities and strong differences between the black and Hispanic mothers. In contrast to the Hispanic mothers, most black mothers had attended schools in the United States, were native speakers of English, and were familiar with what would be required of their children during the elementary school years. They anticipated the demands of elementary school and spent more time teaching their children academically related skills. Mothers' estimates of the degree to which the children were able to perform such skills before first grade were related to their later performance in reading and mathematics.

Black mothers were positive about their child's skills and abilities and had high evaluations of the child's achievements in reading and mathematics. This was also the case with the black children. In comparisons of themselves to other children in their class, they believed that they worked hard in reading and mathematics and that they were doing well in these subjects. Surprisingly, however, their self-evaluations of their skills in reading and mathematics were unrelated to their actual level of achievement. Such a lack of validity in the black children's self-ratings of their academic status seems to indicate that the children had not received, or had not effectively incorporated, reliable and appropriate feedback about their performance in school. This interpretation is in accord with a proposal of Bock and Moore (1986), who suggest that community norms and expectations for student achievement largely determine the standards and types of instruction provided by teachers. If norms and expectations are low, as Bock and Moore presume them to be in many schools attended by minority children, the outcome in terms of academic achievement is also likely to be low. In turn, if the norms are low, parents and children may tend to overestimate children's degree of success in school. This would result, therefore, in a tendency for many minority children to evaluate themselves on the basis of standards that are not appropriate for students in their grade in school.

Alternatively, Alexander and Entwisle (1988) have suggested that the interpersonal support provided by black parents is often unconditional and therefore may lack credibility and may not be informative to their child in matters related to school. Black parents, they propose, value school and want to encourage high levels of accomplishment for their children, but despite these good intentions may "lack the experience, knowledge base, and personal resources for effective followthrough" (p.110). Black, and presumably also Hispanic, children may be less effective than white children, therefore, in gaining a realistic concept of how well they are doing in school.

Whitefamilies. - The needs and daily experiences of white families form the core around which the American elementary school cumculum is fashioned; thus both from their own school experiences and from their current experiences with their child, the white mothers were in a good position to interpret the goals and expectations of the elementary school. The white mothers, like the black and Hispanic mothers, were astute in evaluating their children's academic abilities, but they were less enthusiastic about the value of education, the utility of assisting children outside of school, and the necessity of such things as homework and competency testing. The general impression given by the white mothers was that they were satisfied with the way things were going for their child and that they found little need to assume a more central role in their child's education.

\section{Ethnic Similarities and Differences}

Although the mean scores of minority children were below those of white children in mathematics, levels of achievement after the first grade did not differ significantly when mothers' education and family income were controlled. Children of poorly educated mothers, whether black, white, or Hispanic, did less well in mathematics than did children whose mothers had higher levels of education. This was not the case with reading. Ethnic differences remained statistically sig- 
nificant after the effects of mothers' education and family income had been removed. Our interpretation of this finding is that the content of the material the children were asked to read was based on experiences and knowledge that were less likely to be part of the daily lives of the black and Hispanic than of the white children. Comprehending the meaning of text is difficult when the topics lie outside the child's everyday experience. Hispanic children bore the additional burden of being asked to read a language that typically was not the native language of their parents. The content of reading classes, more than that of mathematics classes, reflects situations that exist in the dominant culture. Minority children may be penalized in reading because the materials require information to which they have had less exposure outside of school than the white children have had. However, our use of tests based on the textbooks to which the children had been exposed may have been responsible for reducing the magnitude of ethnic differences in this study compared to studies that have relied on standardized tests of achievement. Typically, standardized achievement tests are based on what children are expected to know, rather than on what they necessarily have encountered.

The beliefs and attitudes expressed by the mothers and children are in agreement with findings of other recent studies that provide a positive picture of educational aspirations for black and Hispanic children in the United States (e.g., Bartz \& Levine, 1978; Hare \& Castanell, 1985). Despite adverse economic situations and other social impediments, the black and Hispanic families represented in this study had enthusiastic attitudes about education and attempted to provide supportive environments for academic achievement in their young children. The majority of black and Hispanic mothers and children were interested in education and positive about future educational prospects. The children had high expectations about their future success; they showed initiative and selfdiscipline; they displayed self-direction, high self-esteem, and high desires for achievement. The minority families often lived under difficult economic and social conditions, but the mothers had strong interests in their child's schooling; they were enthusiastic about education; and they held high expectations about their child's future educational opportunities. It is readily evident to minority families in the United States that the major avenue for social and economic advancement is through education. The enthusiasm expressed by the black and Hispanic mothers about ways in which they and the schools could provide an effective education for their children appears to be derived fiom this awareness.

To summarize, our results indicate, first, that the achievement level of black and Hispanic elementary school children is not substantially lower than that of white children of similar socioeconomic status, and, second, that the beliefs of minority children and their mothers are similar to those typically associated with higher, not lower, levels of achievement.

These results would not lead us to predict the high rates of school failure and of school dropout that occur among minority youth in junior high school and high school. The positive motivation that is evident during elementary school is obviously not sustained by many minority adolescents. Something must occur after the elementary school years that has a destructive effect on their motivation for academic achievement. It is appropriate to speculate about possible reasons for this marked discrepancy between what occurs in elementary school and in later years of schooling. Several interrelated reasons can be suggested. Reed (1988), for example, has argued that tracking often results in an overrepresentation of minority students in lower tracks, and that the lack of stimulation in these tracks may reduce their motivation to achieve. Reed also suggests that motivation may be reduced when teachers and school officials convey an expectation to minority students that they are less capable of high levels of achievement than are other students. Faced with such expectations, many minority students may cease trying to achieve. Finally, he suggests that the lack of discipline in many schools may deprive minority children of opportunities to learn by allowing them to cut classes and to attend classes without completing their work. Other reasons can also be offered.

First, the curricula in junior and senior high school are relatively more difficult than those encountered in elementary school. For many students, the greater demands posed by these cumcula may transform school fiom the place of success that it appeared to be in elementary school to one of potential failure. Rather than risk a possible decline in selfesteem that would result from failure, students may cease trying to achieve. This possibility is especially likely to occur if the 
students have not acquired the skills and knowledge expected of students entering secondary school. The results of the achievement tests given in this and other studies indicate that this is the case for many minority students, thereby providing the conditions necessary for a decline in motivation.

A second possibility is based on the suggestion by Willig et al. (1983) that many minority adolescents may not consider the classroom to be a relevant domain for achievement. Incentives outside the classroom may gradually assume a greater value for these youth, with a resulting decline in motivation for academic achievement.

A third possibility is that many minority students in junior and senior high school find it difficult to see the relation between their efforts and the rewards that are available to them in American society. Through increased exposure to friends and nonparental adults, they become disillusioned about the possibility that continued diligence and devotion to their schoolwork will eventuallv enable them to advance their social and economic status. This, coupled with their growing awareness of the racism with which they may be faced in society, leads many minority children to shift, as Ogbu (1986) has suggested, from a belief system that values education to an alternative belief system that is more commensurate with their relatively low chances of attending college and attaining a prestigious career.

The early years of junior high school appear, therefore, to be a critical time for intervention aimed at preventing the decline in motivation of many minority children for academic achievement. If we are to understand the phenomenon of school dropouts of minority students, we must not seek explanations only within minority families, but we must look at the process and purposes of schooling itself.

\section{References}

Alexander, K L., \& Entwisle, D. R. (1988). Achievement in the first 2 years of school: Patterns and processes. Monographs of the Society for Research in Child Development, 53(2, Serial No. 218).

Allen, W. R. (1985). Race, income and family dynamics: A study of adolescent male socialization processes and outcomes. In M. B. Spencer, G. K. Brookins, \& W. R. Allen (Eds.), Beginnings: The social and affective development of black children (pp. 273-292). Hillsdale, NJ: Erlbaum.

Bachman, J. G., \& O'Malley, P. M. (1984). Black- white differences in self-esteem: Are they affected by response styles? American Journal of Sociology, 90, 624-639.

Bartz, K. W., \& Levine, E. S. (1978). Childrearing by black parents: A description and comparison of Anglo and Chicano parents. Journal of Marriage and Family Living, 40, 707-719.

Bennett, W. (1988).American education: Making it work. Washington, DC: Government Printing Office.

Bock, R. D., \& Moore, E. G. J. (1986). Advantage and disadvantage: A profile of American youth. Hillsdale, NJ: Erlbaum.

Clark, R. M. (1983).Family life and school achievement: Why poor black children succeed orfail. Chicago: University of Chicago Press.

Fulkerson, K., Furr, S., \& Brown, D. (1983).Expectations and achievement among third-, sixth-, and ninth-grade black and white males and females. Developmental Psychology, 19, 231236.

Hare, B. R., \& Castanell, L. A., Jr. (1985). No place to run, no place to hide: Comparative status and future prospects for black boys. In M. B. Spencer, G. K. Brookins, \& W. R. Allen (Eds.), Beginnings: The social and affective development of black children (pp. 201-214). Hillsdale, NJ: Erlbaum.

Holliday, B. G. (1985). Towards a model of teacherchild transactional processes affecting black children's academic achievement. In M. B. Spencer, G. K. Brookins, \& W. R. Allen (Eds.), Beginnings: The social and affective development of black children (pp. 117-130). Hillsdale, NJ: Erlbaum.

Humphreys, L. G. (1988). Trends in levels of academic achievement of blacks and other minorities. Intelligence, 12, 231-260.

Madaus, G. F., Kellaghan, T., Rakow, E. A., \& King, D. J. (1979). The sensitivity of measures of school effectiveness. Harvard Educational Review, 49, 207-230.

Matute-Bianchi, M. E. (1986).Ethnic identities and patterns of school success and failure among Mexican-descent and Japanese-American students in a California high school: An ethnographic analysis. American Journal of Education, 91, 233-255.

McAdoo, H. P., \& McAdoo, J. L. (Eds.). (1985). Black children: Social, educational and parental environments. Beverly Hills, CA: Sage.

Neisser, U. (Ed.). (1986). The school achievement of minority children: New perspectives. Hillsdale, NJ: Erlbaum.

Norman, C. (1988). Math education: A mixed picture. Science, 241, 408-409.

Ogbu, J. U. (1985). A cultural ecology of competence among inner-city blacks. In M. B. Spencer, G. K. Brookins, \& W. R. Allen (Eds.), Beginnings: The social and affective develop- 


\section{Stevenson, Chen, and Uttal}

ment of black children (pp. 45-66). Hillsdale, NJ: Erlbaum.

Ogbu, J. U.(1986). The consequences of the American caste system. In U. Neisser (Ed.), The school achieuement of minority children (pp. 19-56). Hillsdale, NJ: Erlbaum.

Ramirez, M., \& Castaneda, A. (1974). Cultural democracy, bicognitiue development, and education. New York: Academic Press.

Reed, R. J. (1988). Education and achievement of young black males. In J. T. Gibbs (Ed.), Young, black and male in America: An endungered species (pp. 37-97). Dover, MA: Auburn House.

Slaughter, D. T., \& Epps, E. G. (1987). The home environment and academic achievement of black American children and youth: An overview. Journal of Negro Education, 56, 3-20.

Spencer, M. B. (1985). Racial variations in achieve- ment prediction: The school as a conduit for macrostructural cultural tension. In H. P. McAdoo \& J. L. McAdoo (Eds.), Black children: Social, educational and parental environments (pp. 85-112). Beverly Hills, CA: Sage.

White, K. R. (1982). The relation between socioeconomic status and academic achievement. Psychological Bulletin, 91, 461-481.

Willig, A. C., Harnisch, D. L., Hill, K. T., \& Maehr, M. L. (1983).Sociocultural and educational correlates of success-failure attributions and evaluation anxiety in the school setting for black, Hispanic and Anglo children. American Educational Research Journal, 20, 385-410.

Yando, R., Seitz, V., \& Zigler, E. F. (1979).Intellectual and personality characteristics of children: Social-class and ethnic-group differences. Hillsdale, NJ: Erlbaum. 